\title{
O PROJETO ALVORADA NO INSTITUTO FEDERAL DE GOIÁS: RESSOCIALIZAÇÃO DE EGRESSOS DO SISTEMA PRISIONAL
}

\author{
The Alvorada Project in Instituto Federal de Goiás: Rehabilitation of Former Prisoners
}

\author{
Priscila de Lima Gomes ${ }^{1}$ \\ Léia Adriana da Silva Santiago ${ }^{2}$
}

\begin{abstract}
Resumo: Esta pesquisa buscou analisar os desafios e possibilidades de ressocialização do egresso do sistema prisional, por meio do Projeto Alvorada, ofertado no Instituto Federal de Educação, Ciência e Tecnologia de Goiás. A reintegração deve transpor os muros do presídio, priorizando a educação profissional como possibilidade de inclusão social. Assim, é imprescindível que os espaços educacionais assumam o compromisso de promover a ressocialização e, ainda, preparem essas pessoas para o mundo do trabalho. A metodologia consistiu em um processo dialético entre documentos escritos e oralidade. Foi utilizada a abordagem qualitativa com elaboração de estudo de caso, baseado na pesquisa bibliográfica do tipo documental e fontes orais. Como procedimentos de coleta de informações, utilizou-se a observação, entrevistas semiestruturadas e grupo focal. Os resultados remeteram a uma lacuna na reinserção dos egressos do sistema penitenciário à sociedade. Esta pesquisa mostrou as fragilidades na execução do Projeto Alvorada no que tange à promoção da educação profissional necessária ao público.
\end{abstract}

Palavras-chave: Educação profissional. Egresso do sistema penitenciário. Reinserção ao convívio social.

\begin{abstract}
This research aimed to analyse the challenges and possibilities of rehabilitation of former prisoners through the Alvorada Project, offered by Instituto Federal de Educação, Ciência e Tecnologia de Goiás. The reintegration must go beyond the prison walls, prioritizing professional education as a possibility for social inclusion. Thus, it is essential that the educational spaces take the responsibility to promote rehabilitation and, yet, prepare these people for the field of work. The methodology consisted of a dialectic process through written and oral documents. The qualitative approach was adopted, with the research consisting of a study case, based on bibliographical research of documental type and oral sources. As data collection, procedures, observations, semi-structured interviews and focal groups were used.
\end{abstract}

\footnotetext{
${ }^{1}$ Mestre em Educação Profissional e Tecnológica - ProfEPT, junto ao Instituto Federal de Educação, Ciência e Tecnologia Goiano (IF Goiano). Graduada em Pedagogia pela Universidade Federal de Goiás (UFG). Pedagoga no Instituto Federal de Educação, Ciência e Tecnologia de Goiás (IFG). Orcid: 0000-0001-7986-5653. E-mail: priscila.gomes@ifg.edu.br

2 Doutora em Educação pela Universidade Federal do Paraná. Mestre em Educação pela Universidade Federal de Santa Catarina. Graduada em História pela Universidade Federal de Santa Catarina. Professora do Mestrado Profissional em Educação Profissional e Tecnológica - ProfEPT do Instituto Federal de Educação, Ciência e Tecnologia Goiano - IF Goiano. Orcid: 0000-0002-6057-6808. E-mail: leia.adriana@ifgoiano.edu.br
} 


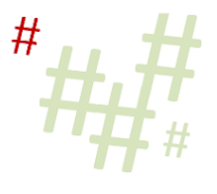

The results led to a gap in the reintegration of former prisoners into society. This research demonstrated the fragilities in the execution of Alvorada Project, regarding the professional education.

Keywords: Professional education. Former prisoners. Reintegration into social life.

\section{Introdução}

Regularmente, as mazelas do sistema penitenciário brasileiro, como carência de políticas públicas penais, falta de infraestrutura, superlotação, rebeliões, são noticiadas por emissoras de televisão e jornais. Compreender essas questões que assolam os presídios e refletir sobre seus aspectos é um papel muito importante o qual precisa ser assumido pela sociedade, pois não se trata apenas de um problema de segurança pública, senão de um problema social. O sistema prisional é negligenciado pelo poder público e muitas vezes também pela sociedade, que age com desprezo em relação à população carcerária.

No Brasil, há cada vez mais pessoas sendo enclausuradas. De acordo com os dados recentes do Levantamento Nacional de Informações Penitenciárias (Infopen), no ano de 2017, a população carcerária brasileira compreendia 726.354 pessoas e, deste total, 20.638 pertencem ao estado de Goiás, recorte empírico deste trabalho. Esse número se deve, além de outros fatores, à lentidão nos julgamentos dos processos.

Uma vez cumprida a pena, contudo, o indivíduo é posto em liberdade e se torna egresso do sistema prisional, o que dá início a um novo e desafiador processo de reinserção ao convívio social. Segundo Pontes (2013), essas pessoas, na maioria das vezes, possuem pouco ou nenhum poder aquisitivo, baixa escolaridade e pertencem a comunidades de periferias, já sendo, pois, desde antes do encarceramento, excluídas dos acessos aos bens sociais. De fato, em relação ao grau de escolaridade das pessoas que cumprem penas privadas de liberdade no Brasil, o Infopen destaca que 51,3\% destas possuem o ensino fundamental incompleto, seguido de 14,9\% com ensino médio incompleto e $13,1 \%$ com ensino fundamental completo. O percentual de $0,5 \%$ corresponde a população carcerária que possui a educação superior completa. Consequentemente, mais da metade das pessoas encarceradas possuem baixa escolaridade.

Em um país que não investe em educação para as pessoas que gozam da liberdade e menos ainda para aquelas que estão encarceradas, é desafiador pensar que um dia a realidade do sistema penitenciário será melhor, mais humana e voltada para a reinserção ao convívio com a comunidade extramuros. Tal contexto é preocupante e se converte em denúncia de um Estado que não garante nem o básico, ou seja, os direitos fundamentais assegurados pelo artigo $6^{\circ}$ da Constituição Federal referentes à educação, saúde, trabalho, previdência social, lazer, segurança, proteção à maternidade e à infância e assistência aos desamparados (BRASIL, 1988), que visa à qualidade de vida dos menos favorecidos, a fim de possibilitar a igualdade social.

No Brasil, não há pena de morte ou prisão perpétua, sendo, por longo período, 30 anos o tempo máximo de reclusão permitido pelo Código Penal a quem comete crime. Todavia, no dia 24 de dezembro de 2019 foi sancionada pelo então presidente, Jair Bolsonaro, a Lei 13.964/2019 a qual aumenta para 40 anos o tempo máximo de cumprimento das penas privativas de liberdade no país. Partindo dessa premissa, em algum momento após o encarceramento, a pessoa será posta em liberdade para retomar sua vida em sociedade. Depois de ter cumprido pena longe de seus familiares, afastado da escola, do mundo do trabalho e de outros direitos essenciais para obtenção de qualidade de vida, é fundamental o apoio e 
acolhimento da sociedade e do governo para a superação desses desafios e a promoção do harmônico convívio.

Não poderia deixar de destacar o contexto em que se vive hoje e que afetou o mundo, o período de pandemia provocada pelo novo Coronavírus (COVID- 19). Muitas pessoas têm sofrido as consequências da doença, mortes, falta de emprego, fome e isolamento social, porém, dentre elas está a população carcerária, sobre a qual pouco se fala. $\mathrm{O}$ coronavírus tem causado grande impacto no sistema prisional, devido às medidas de segurança que foram adotadas para evitar o contágio da doença. Os apenados estão há meses sem receber visitas de seus familiares e sem, consequentemente, os mantimentos, roupas e medicamentos que eles levavam. Ademais, vivem em local nocivo para a saúde, infestado por insetos, não possuem condições de higiene necessárias para se protegerem e para o enfrentamento das doenças.

Para além da COVID-19, as condições insalubres que já existem há muito tempo potencializam a contaminação por inúmeras doenças e, por conseguinte, a propagação, haja vista a superlotação dos presídios. São poucos os profissionais da área de saúde para atender tantos presos, portanto, ainda que conseguissem atendê-los, não é coerente que voltem para o mesmo local em que desenvolveram a doença. A situação apresentada é muito preocupante, afinal, conforme noticiado em 06/05/2020 pelo Universo Online (UOL) e outros jornais, o Ministério da Saúde anunciou que o Brasil registrou 8.536 mortes causadas pelo novo coronavírus, e, segundo os dados da Universidade John Hopkins, o Brasil ocupa o $6^{\circ}$ lugar no ranking mundial de óbitos decorrentes da doença. Pensando nesse contexto, os maiores afetados por esta pandemia serão os negros e pobres, pois são aqueles que possuem maior vulnerabilidade econômica e social, não possuem acesso aos bens para se prevenirem do vírus $\mathrm{e}$, muitas vezes, se encontram presos dentro das celas do sistema prisional.

Assim sendo, este artigo, fruto da dissertação de mestrado publicada pela autora ${ }^{3}$, busca apresentar os desafios e possibilidades de humanização e emancipação do egresso do sistema prisional no processo de reinserção no mundo do trabalho por meio da educação profissional ofertada pelo Projeto Alvorada, do Instituto Federal de Goiás. Para tal, apresentam-se como objetivos específicos do trabalho: verificar qual a percepção do egresso quanto à participação e a oferta do referido projeto como possibilidade de reinserção ao convívio social, bem como identificar a importância da educação profissional para ele.

Ressocialização, reinserção social, reintegração social, reinserção ao convívio social, humanização e educação profissional são conceitos que balizaram a pesquisa e estão presentes neste artigo. Com exceção dos termos "humanização" e "educação profissional", os demais serão utilizados como sinônimos, haja vista que muitos estudiosos os utilizam para representar o mesmo significado. Portanto, "ressocialização", embora possa remeter ao sentido de que o reeducando estava totalmente fora da sociedade, não é essa a compreensão que esta pesquisa apresenta. A ressocialização denota que, quando do retorno para o convívio em sociedade, o indivíduo possa participar socialmente das práticas e atividades enquanto cidadão, tendo não somente seus deveres resguardados, mas também seus direitos.

Acerca do conceito de ressocialização, Julião (2009) explica que, da maneira como está sendo compreendido e empregado no interior do sistema penitenciário moderno, ele se calca sobre o sentido de capacitar o interno a retornar à sociedade disposto a cumprir as normas sociais, garantindo, por essa via, a sua cidadania.

\footnotetext{
${ }^{3}$ O projeto de pesquisa que originou a dissertação supracitada e, por conseguinte, este artigo, foi aprovado pelo Comitê de Ética em Pesquisa com Seres Humanos do Instituto Federal de Educação, Ciência e Tecnologia de Goiás, por meio do CAAE 14146419.5.3001.8082.
} 
$\mathrm{Na}$ atualidade, se dizendo obedecer aos princípios do respeito à pessoa e liberdade humana, o direito penal explicita, contraditoriamente, uma preocupação em considerar os direitos humanitários dos criminosos, alegando que o objetivo da pena não é tanto o castigo, mas sim a sua recuperação, a fim de (re) integrá-los na sociedade, tornando-os dóceis e úteis. Agrega-se a ideia de punição a de reinserção, reabilitação social, ressocialização, com o sentido de passar a respeitar as leis. (JULIÃO, 2009, p. 66).

O conceito do termo ressocialização, segundo Capeller (1985), se deu no século XIX, a partir do desenvolvimento das ciências sociais comportamentais. A autora explica que o discurso jurídico se apropria da definição de ressocialização com o sentido de reintegração social dos sujeitos enquanto pessoas que possuem direitos, ocultando então a ideia do castigo, encobrindo a violência do Estado. Capeller critica o conceito de ressocialização, conforme está posto, diante do contexto do sistema prisional, conforme nota-se na citação abaixo.

\begin{abstract}
$\mathrm{Na}$ sociedade brasileira, hoje, o conceito de ressocialização estaria falido? Aparentemente, em uma resposta ingênua, diríamos que sim. Mas, na verdade, ele é sempre requisitado de modo novo, transformado e transposto para uma nova utilidade. Quando o sistema penitenciário mostra, pelo exercício real da violência, sua verdadeira face apressam-se os políticos e administradores do sistema em resgatar o conceito de ressocialização, prometem verbas federais para construção de novos complexos penitenciários, desviam e deslocam o conflito para esfera do mitológica, apresentam o mito da ressocialização como a única possibilidade dos indivíduos alijados serem felizes novamente e retornarem ao convívio social. (CAPELLER, 1985, p. 132).
\end{abstract}

Discutindo sobre o significado que abarca a ressocialização, Julião (2009) considera que,

[...] partindo do pressuposto que ressocializar tenha o sentido de socializar novamente, percebemos que lidamos com um conceito utilizado basicamente no interior do sistema penitenciário, que implica a ideia de que o interno volte à sociedade disposto a aceitar e seguir as normas e as regras sociais. (JULIÃO, 2009, p. 67).

Shecaira e Corrêa Junior (1995) afirmam que ressocializar é a efetiva reinserção social, a criação de mecanismos e condições, a fim de que a pessoa possa retornar ao convívio social sem traumas ou sequelas, podendo então viver uma vida normal. Neste sentido, é necessário observar a composição dos três pilares fundamentais que compreendem a educação, a qualificação profissional e o trabalho, pois juntos são capazes de preparar o indivíduo para retornar ao convívio social.

Do ponto de vista metodológico, o trabalho realizado na dissertação se constituiu como um estudo de caso de natureza qualitativa, iniciado com a pesquisa bibliográfica, em que foi realizado o levantamento das produções acadêmicas acerca da oferta da educação profissional para egressos do sistema penitenciário, e posteriormente se deu a pesquisa documental e o trabalho com as fontes orais, tendo como instrumento de coleta de dados a entrevista do tipo semiestruturada, a observação, o diário de pesquisa e o grupo focal. Para garantir o anonimato dos participantes das entrevistas, os professores foram identificados pela letra $\mathrm{P}$ e os egressos pela letra E, acompanhados por sequência numérica. 
Deste modo, nas linhas que se seguem vamos apresentar em dois subtemas os dados coletados junto às fontes orais, no diálogo com os documentos escritos, a pesquisa bibliográfica e os conceitos expostos nesta introdução.

\section{0 papel da Educação Profissional relatado por professores e alunos do Projeto Alvorada}

Conforme a Lei de Diretrizes e Bases da Educação Nacional (LDBEN), a educação profissional e tecnológica (EPT) é uma modalidade educacional cuja finalidade essencial é a preparação "para o exercício de profissões" de modo a colaborar para que ocorra a inserção e atuação do cidadão no mundo do trabalho e na vida em sociedade.

No IFG, a educação profissional foi ofertada em consonância com a mútua cooperação do Departamento Penitenciário Nacional (Depen), por meio da execução do Projeto Alvorada: inclusão social e produtiva de pessoas egressas do sistema prisional, Campus Goiânia Oeste, na cidade de Goiânia, por meio do qual foram contempladas 30 (trinta) pessoas egressas do sistema prisional. De acordo com a proposta do referido projeto, ao concluir a sua qualificação profissional, o egresso do curso FIC em Eletricista Instalador Predial de Baixa Tensão deve apresentar um perfil profissional que abarque, além das atividades relacionadas ao curso de eletricista, um comportamento ético, com autonomia e criatividade.

\footnotetext{
Além das habilidades específicas da qualificação profissional, estes estudantes devem estar aptos a:

a) adotar atitude ética no trabalho e no convívio social, compreendendo os processos de socialização humana em âmbito coletivo e percebendo-se como agente social que intervém na realidade;

b) saber trabalhar em equipe; e ter iniciativa, criatividade e responsabilidade (IFG, 2019, p. 31).
}

Tal previsão denota uma correspondência aos preceitos da formação integral, omnilateral do ser humano. Costa (2015) afirma que a educação deve ter como princípio o ensino dos conteúdos científicos, por meio de práticas pedagógicas que fortaleçam a relação teórico-prática, cujo propósito é a formação do homem, no sentido de constituição de caráter, de forma que o sujeito seja consciente de si e de seu papel social.

Uma vez levantadas as condições propostas pelo projeto, buscamos apreender nas falas dos professores e alunos como se deu a oferta do Projeto Alvorada e as suas contribuições para a formação dos alunos egressos do sistema prisional. Foi perguntado acerca dos pontos positivos e negativos relacionados ao projeto, sendo que, sobre os pontos negativos, as respostas dos professores foram unânimes em se tratar da distribuição dos recursos financeiros. As falas dos entrevistados destacaram as limitações do projeto, que refletiram na falta de equipamentos durante as aulas, no baixo valor pago referente às bolsas dos alunos e na falta de estrutura do campus para a ministração das aulas práticas em laboratório:

O ponto negativo eu vejo ainda aqui é a questão da logística, porque nós, professores, a gente enfrenta problemas e esses problemas recaem sobre eles. Por exemplo, os recursos, que bom se tivessem os recursos do Projeto garantidos de modo mais organizado para tudo funcionar bem, na hora certa, o projetor está lá, a extensão também, a caixinha de som [...]. (P1, entrevistado em 22/10/2019). 
O ponto negativo é que o valor da bolsa caiu para o aluno e isso faz diferença para ele, 200 reais, 300 reais já é o valor do aluguel do barracão que alguns já relataram pra mim. É claro que a bolsa deveria ser usada para ele vir para o curso, mas o dinheiro faz falta, muitas vezes ele tem que vir a pé, andar 7 ou $8 \mathrm{~km}$ para poder fazer parte do curso, infelizmente o valor da bolsa não pôde ser maior. E eu acho que o Projeto deveria acontecer em um campus com estrutura para poder trabalhar essa parte técnica. Mas aí, historicamente, depois que eu fiquei sabendo que houve uma relutância do campus Goiânia para não acontecer o curso lá, uma resistência... (P2, entrevistado em 29/10/2019).

Os depoimentos acima mostram a importância dos recursos financeiros para que o curso ocorresse de forma profícua e atendesse às necessidades com vistas à melhoria e conservação da infraestrutura física e pedagógica, além das políticas de permanência e êxito dos estudantes. Nesse sentido, nosso questionamento vai à continuidade do Projeto Alvorada, já que este depende dos recursos do Fundo Penitenciário Nacional (FUPEN), gerido pelo Departamento Penitenciário Nacional (DEPEN). Somente os programas que possuem recursos próprios que continuarão vigentes? Que processo de reintegração é esse que quando lida com os excluídos o projeto "morre"? Por que não dar continuidade com os recursos da própria instituição?

Acerca da responsabilidade social da rede federal de educação profissional e neste caso, mais especificamente o IFG, seu PDI declara "democratizar o acesso dos estudantes por meio da adoção das cotas sociais, étnico-raciais e pessoas com deficiências, às/aos alunas/os oriundas/os de escola pública" (IFG, 2019, p. 141). Cabe uma discussão e reflexão sobre as cotas destinadas a presidiários e egressos do sistema prisional, já que estes fazem parte das minorias e estão no grupo de pessoas marginalizadas e excluídas socialmente. É necessário questionar, pois, o direito à educação às pessoas oriundas do sistema carcerário e as cotas e políticas afirmativas capazes de garantir a elas o acesso a todos os níveis de ensino. Os excluídos seguem ainda mais excluídos, pois estes dependem das "Políticas de Estados" e elas chegam ao fim, conforme a "coreografia" política de cada novo governo que assume o executivo e o legislativo do país. Logo, as políticas dos Institutos Federais, no que tange a ressocialização dos egressos do sistema penitenciário, parecem aderir à mesma "coreografia", uma vez que têm apresentando muito mais "políticas de Governo" do que de "Estado".

Desta feita, é imprescindível que sejam realizados investimentos de forma urgente e contínua na qualificação de pessoas oriundas do sistema carcerário, por meio da educação profissional. Conforme evidenciado nos estudos de Pontes (2013), tais investimentos devem ser implementados desde os presídios, de modo que haja continuidade das ações de inclusão após o cumprimento da pena nas instituições penitenciárias.

Historicamente, há um débito no país no que tange ao social e educacional, levando a que se tente minimizar as lacunas determinadas pelo sistema por meio da ampliação da acessibilidade a educação, amplamente defendida. Deste modo, é fundamental garantir que os egressos do sistema prisional tenham condições de serem inseridos no mundo do trabalho, não somente limitados à mão de obra qualificada, mas principalmente como pessoas com criticidade, com consciência de seus direitos e deveres. Assim, é possível intervir e contribuir para que se diminua a exclusão social e a sociedade se torne mais democrática.

Paradoxalmente, existe uma resistência em compreender que os servidores públicos estão a serviço do público, seja ele qual for, pois representam uma instituição pública de ensino que deve ofertar educação gratuita e de qualidade para todos, sem distinção. Nesse sentido, a fala do entrevistado vai ao encontro do que foi colocado acerca da estigmatização e preconceito que está relacionado à pessoa que cumpriu pena no sistema prisional. No entanto, não se pode 
aceitar que algo desumano seja recorrente, principalmente quando o contexto em questão é uma instituição escolar. Gandolfi et al. (2011) explica que diante da falta de oportunidades para a reinserção ao convívio social do egresso e do assédio das facções criminosas para cometer delitos, fica cada vez mais difícil resistir às "pressões das organizações criminosas a que reincidam, o que se torna um circuito de alta voltagem quando consideramos o escasso número de oportunidades que lhes são oferecidas pela sociedade" (GANDOLFI et al., 2011, p. 7).

Os estudos de Wauters (2003) mostram que grande parte dos egressos do sistema carcerário já sofria a marginalização antes da prisão, porém, ao sair do presídio e tentar conviver socialmente, percebe que há uma distância muito maior do que antes, para ter acesso ao trabalho e à educação. A segregação inerente ao cárcere e principalmente o preconceito e desconfiança são fatores que dificultam o processo de ressocialização.

Tratando-se dos pontos positivos do Projeto Alvorada, um dos que foi comentado pelos entrevistados se referiu à possibilidade da reintegração social por meio da educação e do trabalho, seja como trabalhador autônomo ou por contrato. Um dos professores entrevistados também mencionou a formação mais ampla e holística.

O ponto positivo é essa formação mais ampla, essa formação, digamos assim, holística, porque não trabalha só com a parte de conhecimento técnico, mas amplia para português, matemática, uma visão para empreendedorismo. Porque muitas vezes ele pode até não se embrenhar na área técnica, mas se ele tem uma percepção de que ele pode abrir um pequeno negócio para ele. (P2, entrevistado em 29/10/2019).

Contudo, embora os documentos do Projeto Alvorada sinalizem a formação integral, garantida através da educação e do desenvolvimento dos estudantes em todas as suas dimensões, não foi possível a sua total aplicabilidade, conforme descrito no projeto, uma vez que, de acordo com o relato dos estudantes, houve dificuldade em integrar a formação básica e a formação específica, ficando desarticulada a teoria e prática, comprometendo o processo de ensino-aprendizagem.

Pensando na formação do sujeito, como colocado pelo professor entrevistado do parágrafo acima, Gandolfi et al., (2011), assim como Pontes (2013), constataram a necessidade de oferecer formação continuada e de qualidade ao egresso, com vistas a adquirir ou aperfeiçoar as suas habilidades profissionais.

É importante proporcionar ações que mostrem aos alunos que eles são sujeitos de direitos, que possuem dignidade e que por meio do processo de educação pode ser possível traçar novos objetivos para suas vidas, longe da criminalidade. Julião (2011) defende que as ações educativas devem influenciar de modo edificante a vida do egresso, proporcionando condições para que sua identidade seja moldada e ele busque, principalmente, compreender e aceitar que é um indivíduo social e nesta perspectiva, construir seu projeto de vida, definindo novos caminhos para que possa viver em sociedade. Frente a isso, Vieira (2014) afirma que:

[...] tal educação requer não apenas formação que articule a competência científica e técnica com a inserção política e a postura ética, mas também a capacidade de produzir e aplicar os conhecimentos técnicos e científicos, através de critérios de relevância social e ética. (VIEIRA, 2014, p. 8). 
Quanto aos relatos dos alunos apreendidos por meio do grupo focal, questionamos sobre a participação no projeto e as contribuições para as suas vidas. Foi interessante observar que os estudantes manifestaram preocupação a partir da comparação que fizeram em relação às disciplinas de formação básica e às disciplinas específicas. As disciplinas básicas são de cunho teórico, já as específicas apresentavam maior aproximação com a área em que iriam atuar. Embora os entrevistados tenham afirmado reconhecer a intenção do projeto em reinseri-los ao convívio social, estes chamaram a atenção para a área técnica, a qual foi pouco explorada, pois tiveram poucas aulas práticas, o que prejudicou a aprendizagem da turma.

\begin{abstract}
Eu acho que o IFG na vontade de nos ajudar a reintegrar a sociedade ele se perdeu nesse curso e implantou várias matérias que não tem nada a ver com eletricidade. Eu entendi qual foi o propósito dele, foi nos reintegrar na sociedade, nos dar algo que a gente já tinha esquecido, mas para o curso em si deixou muito a desejar. Tem muitos aqui que vai sair desse curso sem nem saber cortar um fio, essa é a verdade. Eu acho que foi mais foi vontade de nos reintegrar na sociedade e esqueceu um pouco do curso, mas para mim foi bacana. (E4, entrevistado em 11/11/2019).
\end{abstract}

Eu esperava mais de eletricidade, e eu acho que ficou faltando assim eletricidade, na prática mesmo. Porque dividiu a eletricidade e as outras matérias, eu acho que poderia ter sido uma parte maior de eletricidade e assim deixado $30 \%$ pra outras matérias, ai seria melhor, teria melhor proveito. (E13, entrevistado em 11/11/2019).

A partir da fala do estudante que denota certa frustração em relação à forma em que o projeto ofertou as aulas práticas, os estudos de Oliveira (2009) e Lemos, Mazzilli; Klering (1998) destacam que para que ocorra a reintegração do indivíduo ao convívio social por meio do trabalho, é importante que este possibilite o seu desenvolvimento pessoal, utilizando e aprimorando sua capacidade de percepção, bem como suas habilidades para a resolução de problemas complexos ou para situações que exijam criatividade e inovação, dentro de um processo real de trabalho.

Nas falas, é possível perceber que embora o curso tenha contribuído para o processo de reinserção ao convívio social e para novas aprendizagens, faltou uma maior integração entre a teoria e a prática e isso fez com que muitos alunos chegassem ao final do curso sem os conhecimentos mínimos para exercer a profissão.

\footnotetext{
A intenção do IFG foi reintegrar as pessoas, atualizar no caso a profissão, não só ter uma profissão, como falar, calcular, empreender, administrar, essa foi à intenção do IFG que foi boa, e assim como foi o primeiro projeto e não vai ter outro, foi ministrado pelo IFG e ele não vai poder ministrar mais, por questão burocrática, então tudo bem. Se tiver outra oportunidade, outras que vão ter, entendeu? Que seja ministrado completamente, pra pessoa não sair $75 \%$, mas $100 \%$, porque os outros $15 \%$ que ela perdeu ela não vai recuperar mais, porque a maioria que tá aqui é inclusive por questão de classe social. (E5, entrevistado em 11/11/2019).

Mas é igual o colega falou, que nem todos aqui vai sair daqui $75 \%$, não vou colocar nem $100 \%$, não vai sair daqui nem $75 \%$. Alguns vai sair daqui $30 \%$, outros $40 \%$, alguns vai sair $100 \%$ porque é igual ele falou, já tinha uma noção já de eletricidade. Então teve outras aulas também que nos fez a ser diferente, eu particularmente, eu quando vim pra cá eu vim com uma visão, foi depois que eu comecei a fazer o curso, ter as aulas, o contato com os outros menino aí eu já comecei a ter uma visão diferente, tanto da sociedade, do sistema prisional e da escola. (E7, entrevistado em 11/11/2019).
} 
Outro ponto levantado foi em relação ao horário do curso, com as aulas ministradas no período vespertino, que os impossibilitou de buscarem oportunidades de trabalho. Cabe destacar também as falas no que diz respeito ao valor das bolsas pagas aos estudantes, pois inicialmente o valor seria de $\mathrm{R} \$ 1.076,00$ por aluno, mas, com o contingenciamento, foi reduzido para $\mathrm{R} \$ 700,00$. A bolsa paga aos estudantes representa muito para eles, pois a maior parte está desempregado e necessita pagar despesas do dia a dia, como transporte, aluguel e alimentação para manterem suas famílias. Esse perfil de vulnerabilidade socioeconômica foi constatado em todas as pesquisas do levantamento bibliográfico. Portanto, mesmo diante das dificuldades que eles apontaram em fazer o curso, afirmaram não desistir, pois acreditavam que seria uma oportunidade para transformarem as suas vidas.

Cada um que tá fazendo esse curso Alvorada aqui eu acho que quer oportunidade, quer ser alguma coisa, porque se a gente não quisesse, ninguém ia vir aqui não, pra ganhar 700 reais, 700 reais não sustenta a família da gente não, não sustenta. Mas a gente tá aqui lutando, fazendo esforço e tudo porque a gente dentro do coração quer ser outra pessoa. (E6, entrevistado em 11/11/2019).

Em questão da bolsa que a gente recebe, era para ser um valor e, devido a algo dos projetos do governo, não sei o que houve certinho, diminuiu. Em questão do horário do curso, como foi falado, que interrompe a gente de estar fazendo algo para estar levando o sustento para dentro de nossa casa. (E2, entrevistado em 11/11/2019).

Então, assim, esse Projeto e esse curso veio a somar na minha vida, entendeu? Apesar de estar sendo em um horário mais difícil porque a gente não pode arrumar um serviço, entendeu? Então, assim, muita gente está deixando de fazer muita coisa para ter o término do curso, entendeu? Para não ter que desistir e focar mais no curso, entendeu? Então, muita gente está fazendo isso aqui, mas praticamente assim bem apertado mesmo, está sendo bem difícil mesmo, por conta do horário. (E1, entrevistado em 11/11/2019).

Observamos que os alunos trouxeram em suas falas as limitações em relação ao horário de aulas e as dificuldades, na execução do curso, em estabelecer a relação entre a teoria e prática, entretanto, a questão de disponibilizar ao egresso uma formação integral, que tem como pressuposto a educação para o desenvolvimento de capacidades intelectuais, práticas e morais, não se limitando somente à formação do indivíduo para atender as demandas do mercado de trabalho, está presente nos documentos prescritos do Projeto Alvorada.

Essa formação ampla que compreende o ser humano como um todo concerne a "[...] um desenvolvimento multilateral, em todos os sentidos das faculdades e das forças produtivas, das necessidades e da capacidade de satisfação" (MANACORDA, 2010, p. 94). Para uma formação integrada, conforme estabelecido pela escola "unitária", defendida por Gramsci (2001), é essencial que haja a integração da teoria com a prática, relacionando as partes com o todo, bem como o trabalho como princípio educativo. É preciso romper com a dualidade histórica que faz parte das sociedades de classe, voltadas para as demandas do mercado em detrimento da formação humana integral. Neste contexto, é importante pontuar a relevância da relação teoriaprática no efetivo processo de ensino-aprendizagem do estudante, de forma indissociável, não por uma visão dicotômica, mas de modo a propiciar a compreensão dos significados, bem como a integração existente entre a teoria e a prática profissional. Conforme declarado no Projeto Político Institucional do IFG: 
faz-se necessário romper com a fragmentação do saber, buscando entrelaçar teoria e prática, pensar e fazer, ciências exatas, da natureza e ciências humanas, posto que o Currículo Integrado Omnilateral seja assumido institucionalmente como a forma correta e necessária de se estabelecer em todos os níveis e modalidade no IFG (IFG, 2019, p. 107).

Isso leva a inferir que, nos documentos, a proposta do projeto contempla a formação integral dos estudantes, no entanto, não foi possível contemplar no dia a dia da sala de aula, uma vez que foi desenvolvido de forma aligeirada e certificatória, com vistas à formação de mão de obra para atuação no mercado de trabalho.

Neste aspecto, foi perguntado aos professores acerca da importância do trabalho na ressocialização do egresso do sistema prisional. A perspectiva mercadológica de preparar o estudante para atender as demandas do mercado foi presente nos discursos dos docentes. Isso expressa a urgência por uma formação profissional que apresente uma visão crítica e problematizadora das relações econômicas no mundo capitalista, que faça os indivíduos compreenderem a necessidade de centralizar o ser humano e não a lucratividade nas relações que envolvem a educação e o trabalho.

\begin{abstract}
Ele precisa entender a lógica do mercado, entender a administração moderna, entender o mercado de trabalho como que funciona atualmente. (P1, entrevistado em 22/10/2019).
\end{abstract}

Se ele já tem um curso com o diploma do IFG já é visto com outros olhos, assim como o diploma do SENAI, já é visto com outros olhos pelo mercado de trabalho. (P2, entrevistado em 29/10/2019).

Nesse aspecto, em seus estudos, Wauters (2003) endossa uma ressocialização do egresso do sistema prisional camuflada na atividade laboral, sob a égide do capital, tendo em vista a profissionalização realizada com o intuito de atender às demandas mercadológicas e, a partir daí, ter sua força de trabalho absorvida pelo mercado. Os depoimentos citados acima exemplificam a concepção da dualidade historicamente construída sobre aos preceitos reducionistas da educação profissional. Em contrapartida, os apontamentos de Pontes (2013) apresentaram em sua pesquisa uma visão mais ampla em relação à formação do indivíduo: "assim, denota-se que a qualificação profissional possibilita, além de maiores chances de inclusão social no mundo do trabalho, uma auto referência para ressignificar suas vidas e ampliar suas possibilidades de escolhas" (PONTES, 2013, p. 8).

Portanto, para o desenvolvimento do sujeito, o ensino deve incluir a aquisição de conhecimentos usados como ferramentas intelectuais, a fim de ampliar a capacidade de pensar e ter consciência de seus atos em sociedade. Pontes (2013) parte do pressuposto de que a educação profissional é um fator que ressocializa o ser humano e mantém o equilíbrio social.

A proposição de ressocialização de presos e egressos do Sistema Penitenciário por meio do trabalho e qualificação profissional baseia-se no pressuposto de que o trabalho é fonte de equilíbrio na sociedade servindo também como agente ressocializador no cárcere. Assim, denota-se que a qualificação profissional possibilita, além de maiores chances de inclusão social no mundo do trabalho, uma auto referência para ressignificar suas vidas e ampliar suas possibilidades de escolhas (PONTES, 2013, p. 8). 
Neste sentido, a autora considera a possibilidade da reinserção de presos e egressos como uma oportunidade de terem acesso também ao mundo do trabalho, tendo em vista a qualificação profissional como um meio de proporcionarem um novo significado às suas vidas. Complementa também acerca da educação profissional que "suas ações visam, ainda, combater a reincidência criminal considerando-se que a partir da qualificação profissional propicia-se aos presos e egressos um maior leque de opções de trabalho e renda" (PONTES, 2013, p. 11).

A educação profissional possui em seu cerne a cultura, a autonomia e a formação integral que defende o processo formativo do sujeito tendo o trabalho como princípio educativo. Para Ramos (2005), a educação politécnica faz a mediação entre a sociedade e o ser humano e, portanto, deve se fazer presente na integração entre trabalho, ciência e cultura no processo de formação do homem.

O trabalho compreendido como realização humana inerente ao ser (sentido ontológico) e como prática econômica (sentido histórico associado ao respectivo modo de produção); a ciência compreendida como os conhecimentos produzidos pela humanidade que possibilita o contraditório avanço produtivo; e a cultura, que corresponde aos valores éticos e estéticos que orientam as normas de conduta de uma sociedade (RAMOS, 2005, p. 3).

Conforme previsto nos artigos 25 e 26 da Lei de Execução Penal, é assegurado ao egresso o direito a ser orientado e apoiado, com vistas a ser reintegrado à vida em liberdade $\mathrm{e}$ de receber assistência social que deve auxiliá-lo na procura de um emprego (BRASIL, 1984). Portanto, embora existam muitos obstáculos que dificultam a reinserção do egresso ao convívio em sociedade, é imprescindível que o Estado ofereça meios para que a lei seja cumprida e o egresso tenha condições de viver como um cidadão de direitos.

Como dito anteriormente, os documentos do Projeto Alvorada coadunam com a concepção de educação omnilateral, que visa à formação de pessoas com capacidade crítica e criativa, para que sejam atuantes na transformação da sociedade. Nesta perspectiva, Ciavatta (2005) enfatiza que,

[...] a formação integrada sugere tornar íntegro, inteiro, o ser humano dividido pela divisão social do trabalho entre a ação de executar e a ação de pensar, dirigir ou planejar. Trata-se de superar a redução da preparação para o trabalho ao seu aspecto operacional, simplificado, escoimado dos conhecimentos que estão na sua gênese científico-tecnológica e na sua apropriação histórico-social. Como formação humana, o que se busca é garantir ao adolescente, ao jovem e ao adulto trabalhador o direito a uma formação completa para a leitura do mundo e para a atuação como cidadão pertencente a um país, integrado dignamente à sua sociedade política. Formação que, neste sentido, supõe a compreensão das relações sociais subjacentes a todos os fenômenos (p. 2- 3).

Todavia, embora as falas do gestor, professores e alunos demonstrassem a importância do Projeto Alvorada para que os estudantes pudessem ter uma nova visão de mundo, retomar os estudos e obter conhecimentos que vão além das disciplinas ministradas, seria necessário ainda percorrer um longo caminho para que aqueles oriundos do sistema prisional usufruíssem da formação omnilateral proposta nos documentos do IFG. Contudo cabe lembrar que utilizei os verbos no tempo passado, porque, como já sinalizei em páginas anteriores, desde dezembro de 2019, o projeto, em função da falta de verbas, não existe mais dentro da instituição. 


\section{Reinserção do egresso do sistema penitenciário ao convívio social}

A reinserção do egresso do sistema penitenciário está preconizada no artigo primeiro da Lei de Execução Penal e constitui um dos objetivos da pena: “Art. $1^{\circ}$ A execução penal tem por objetivo efetivar as disposições de sentença ou decisão criminal e proporcionar condições para a harmônica integração social do condenado e do internado" (BRASIL, 1984, s.p).

As condições em que o egresso se encontra, bem como as oportunidades de trabalho, estudo, a forma como ele é recebido pela sociedade, influencia na reinserção dessa pessoa no mundo do trabalho, nas atividades da comunidade e até mesmo para o seu possível retorno às práticas criminosas. Neste sentido, é fundamental o acolhimento do egresso, de forma solidária, pois contribui para que ele possa superar os preconceitos, estigmas e adversidades que possam vir a surgir. $\mathrm{O}$ tratamento ao egresso como um cidadão de direitos estimula a consciência social e ajuda este a se sentir participante da sociedade, promovendo, assim, a sua autoestima. Ao retornar ao convívio com a sociedade e buscar um novo caminho para viver com dignidade, o egresso precisará de um trabalho para obtenção de renda, se sustentar e também a seus familiares, no entanto, o que se percebe é que ele tem esse direito negado, pois todas as portas são fechadas a partir do momento em que é constatado que se trata de um egresso do sistema carcerário. Embora o Estado crie leis para que o egresso volte ao convívio com as pessoas fora da prisão, ele é incipiente em relação a prover condições para que esse indivíduo consiga vencer os obstáculos devido ao encarceramento.

Os egressos sentem muitas dificuldades em se relacionarem com as pessoas, sentem medo da rejeição, vergonha por terem ficado presos, e esses sentimentos são oriundos das experiências adquiridas dentro do sistema penitenciário. Sobre isso, Mirabete (1988, p. 234) afirma que

[...] a ausência prolongada do condenado de seu meio social acarreta um desajustamento que somente poderá ser superado se forem oferecidas a ele condições adequadas à sua reinserção social quando for liberado. É preciso, pois, que toda a comunidade seja conscientizada da missão que the cabe na tarefa de assistir aquele que, tendo transgredido a lei penal, está resgatando o débito criado com a prática do crime.

O retorno dessas pessoas para uma nova convivência fará com que adquiram novos valores, novas crenças e esperança em reconstruírem suas vidas. Diante disso, foi perguntado aos professores e gestor acerca da importância da educação na ressocialização do egresso do sistema prisional.

Eu acho que estudar é bastante importante para essa formação profissional, eu acredito na formação profissional dessa forma. Então eu acho que tudo isso é importante para que ele depois venha a exercer um papel na sociedade, uma profissão com segurança. Você vê que no projeto eles têm disciplinas do núcleo comum e disciplinas técnicas, isso é muito legal. Eles têm visitas técnicas, eles têm tutoria, isso é muito bom, assistência social, psicológica acho que tem também. (P1, entrevistado em 22/10/2019).

É de suma importância, vem à oportunidade de acreditar em si mesmo, porque o estudo, a educação auxilia nisso, ele acreditar em si. Tinha alunos que não tinham nenhum conhecimento técnico, e com o tempo foi tomando a liberdade de executar as atividades, eu já trazia o material e eles já executavam as atividades de forma independente, junto com os outros, já tendo essa confiança. Então o ensino ele traz essa confiança de acreditar em si, independente da área. Ao acreditar em si ele já começa a ter uma nova visão de mundo também. O trabalho ele vem em consequência desse estudo. (P2, entrevistado em 29/10/2019). 
Todos os participantes declararam que, no processo de reinserção ao convívio social de egressos do sistema carcerário, tanto a educação quanto o trabalho são fundamentais. Uma das falas destacou a relevância da educação profissional, enfatizou as visitas técnicas, tutoria, assistência social e psicológica ofertadas no projeto, além de afirmar o quanto é essencial o aluno se reconhecer e exercer o seu papel na sociedade para, a partir disso, desempenhar uma profissão (P1). Outro entrevistado pontuou sobre a importância da autonomia e da autoestima, propiciadas pela educação, na promoção da reinserção dos egressos na vida em sociedade (P2).

Um ponto comentado pelos entrevistados foi que o sistema prisional deveria ofertar uma educação de qualidade ao recluso para já prepará-lo para a sua liberdade e, no entanto, não oferta. Ao sair da prisão, ele se encontra em um ambiente que o marginaliza, o estigmatiza e fecha todas as portas de oportunidades, impedindo que ele possa conviver em harmonia e dignidade. Essa colocação vai ao encontro da proposição de Rocha et al. (2013) que reforça a necessidade do fortalecimento de políticas públicas que promovam a reinserção ao convívio social e consequentemente ao mundo do trabalho, pois, mesmo com os incentivos do governo, são poucas as instituições que contratam pessoas oriundas do sistema carcerário. Neste sentido, há uma dificuldade quanto à superação do estigma do egresso que interfere até mesmo em relação a sua permanência na organização.

Ao perguntar sobre as sugestões de melhorias para o sistema prisional, todos os entrevistados apontaram a educação como sendo a principal mudança necessária a ser feita nos presídios. Em uma das falas foi evidenciado que a educação é à base de tudo, pois por meio do acesso a ela é possível que o indivíduo não cometa crimes e, consequentemente, não seja um reeducando do sistema prisional (P1). Os outros entrevistados relataram a necessidade de a reinserção social começar dentro do presídio, considerando o processo formativo, crítico e educacional do apenado e não somente após o cumprimento da pena (P2).

É acreditar na educação, mas antes que eles cheguem ao sistema prisional [...] A partir do momento que a escola, para quem tem menos condições, sobretudo econômica, a escola seja melhor, esse indivíduo vai estar mais bem preparado para a vida de maneira que ele não vai parar lá no presídio. (P1, entrevistado em 22/10/2019).

A reinserção tem que acontecer de forma mais rápida, não é manter aprisionado, mas já colocar ele para fazer trabalhos sociais, trabalhos que já ajude ele a repensar o seu papel na sociedade e fazer uma reinserção social. (P2, entrevistado em 29/10/2019).

Essa fala corrobora com as inquietações de Pontes (2013), que diz ser imprescindível investimento de forma urgente na capacitação e qualificação de pessoas oriundas do sistema carcerário, por meio da educação profissional. Conforme evidenciado em seus estudos, esses investimentos devem ser implementados desde os presídios, de modo que haja uma continuidade destas ações de inclusão após o cumprimento da pena nas instituições penitenciárias. Sob o aspecto da reinserção ao convívio social, tendo em vista o Projeto Alvorada, destacam-se algumas falas dos egressos:

Eu acho que colocou muitas matérias pra gente tá reintegrando à sociedade, aprender a falar, expor, tem gente aqui que nunca apresentou em sala de aula, morrendo de vergonha, tremendo, batendo queixo igual eu vi muitos companheiros aqui e aqui quebrou esse paradigma. (E4, entrevistado em 11/11/2019).

[...] Eu pus até no meu perfil do Facebook "estudando no campus Goiânia Oeste do IFG” porque de certa forma é bom, é gostoso isso, é uma emoção que traz pra gente. 
[...] a gente parou de estudar para poder se envolver com as coisas erradas e pela oportunidade que a gente esta tendo aqui, maravilhosamente boa, eu agradeço e muito. (E2, entrevistado em 11/11/2019).

[...] Hoje o que eu sou aqui na rua assim em função de um projeto desse daqui pra me dar uma oportunidade pra mim rever a minha vida de novo, a construir a minha família que eu perdi. Então o que vai ser da minha vida se a sociedade não me acolher, não me der a mão, não me erguer. (E6, entrevistado em 11/11/2019).

[...] o curso trouxe essa visão pra mim, de querer investir mais no meu profissionalismo. Então agradeço primeiramente a Deus, depois o Instituto Federal, aos amigos também aqui que a gente pôde fazer amizade. (E6, entrevistado em 11/11/2019).

Estudar numa faculdade pra mim é uma honra muito grande, eu poder chegar e poder falar: "eu sou um cara que faz faculdade, né eu vim do lixo, mas eu vou chegar ao luxo" [...] Eu agradeço a cada um de vocês por ta acreditando na nossa história, porque se a gente tiver alguém que acredita [...] sabemos que podemos mudar a nossa história. (E9, entrevistado em 11/11/2019).

Essa é uma oportunidade boa que nós tivemos, creio que vai fazer uma diferença em nossa vida sim, com certeza, né porque serão mais portas que irão se abrir e tô satisfeito sim, muito obrigado. (E11, entrevistado em 11/11/2019).

Todos os relatos dos entrevistados egressos do sistema prisional carregam um pouco de dor e sofrimento; uns até se emocionaram ao expor às dificuldades que enfrentaram e que continuam enfrentando devido ao estigma e preconceito. Apesar disso, eles demonstraram alegria e gratidão pela oportunidade de terem acesso à educação por meio do Projeto Alvorada, reconhecendo nessa ação uma possível mediação no ingresso ao mundo do trabalho e uma possibilidade de serem reinseridos ao convívio social. As dificuldades expressadas por eles vão ao encontro das observações de Souza e Silveira (2015) ao constatarem que a pessoa que cumpriu pena no sistema penitenciário precisa lidar com desafios que perpassam a baixa escolaridade, ausência de documentos pessoais e de moradia, bem como a falta de assistência para obter meios de retornar ao convívio social. Esses aspectos somados a outras dificuldades que o egresso enfrenta, desencadeia ou potencializa transtornos psíquicos causados pela vivência no cárcere e também pelo uso abusivo de álcool e outras drogas.

Em suas falas destacaram muito a questão da empregabilidade, haja vista que a maioria se encontra em condição de desempregado. Souza e Silveira (2017) constataram que o trabalho é um fator de inclusão social dentro e fora dos presídios e ainda na (re)construção da identidade do trabalhador, portanto, salientam a importância do emprego para a pessoa egressa do sistema carcerário, pois além de suprir as necessidades materiais, contribui para a motivação, dignidade e autoestima dessas pessoas.

Vimos também que os egressos sentem orgulho de serem alunos do IFG, pois é uma forma de mostrar para a sociedade que eles estão buscando, por meio da educação, não voltar à criminalidade. Outro ponto destacado em relação ao curso foi que ele propiciou até mesmo a perda do medo e da vergonha em falar em público. Os depoentes também expuseram suas esperanças em reatar vínculos familiares, que foram desfeitos com o encarceramento e o acesso a novas oportunidades que poderão surgir para a melhoria de suas vidas.

\section{Considerações Finais}

Nos instrumentos oficiais, foi possível verificar que o cerne do Projeto Alvorada tem como objetivo a inclusão social e produtiva de pessoas egressas do sistema prisional. O Projeto 
Alvorada, assim como o PDI do IFG, traz a concepção de uma educação voltada para a formação omnilateral do indivíduo, compreendendo-o como um todo. Além disso, conforme declarado no referido PDI, mantém a luta pela democratização, no âmbito da instituição, a favor da ampliação de acesso por parte dos segmentos sociais historicamente dela excluídos.

Diante disso, vimos a importância de irmos a campo apreender as percepções dos professores e estudantes que fizeram parte do projeto, ocasião na qual percebemos que a educação profissional, por meio do Projeto Alvorada, possibilitou aos seus alunos novas vivências e aprendizagens em um ambiente que anterior ao curso já não era tão comum no dia a dia dos egressos.

No entanto, houve muitos desafios e resistências em fazer cumprir o direito dos egressos do sistema prisional em terem acesso à educação pública, gratuita e de qualidade. Isso ficou claro nos discursos preconceituosos de gestores, professores e pais de alunos. Além dessa problemática referente ao preconceito e estigma, o projeto foi fragilizado pelo contingenciamento de recursos, fazendo com que ele não fosse executado conforme previsto no plano de trabalho.

Os depoimentos colhidos evidenciam a importância do curso para os alunos como destacaram: calcular, administrar, falar com clareza e se relacionarem melhor com as pessoas. Observamos que, principalmente para a autoestima, o retorno aos estudos especialmente em uma instituição renomada como o IFG foi motivo de muito orgulho, o que despertou o sentimento de pertencimento desses estudantes. No entanto, os alunos também relataram a frustração em não terem tido as aulas práticas suficientes para atuarem com segurança e eficiência na profissão de eletricista predial de baixa tensão. Neste sentido, há uma desvinculação e fragmentação entre teoria e prática no processo de ensino-aprendizagem. $\mathrm{O}$ ensino aligeirado e dissociado remete a uma educação exclusivamente para atender as demandas do mercado, em detrimento da formação humana integral.

Promover a reinserção desses egressos ao convívio social é um grande desafio, pois perpassa por muitas barreiras, como desemprego, baixa autoestima, preconceito e especialmente vontade política. Está na hora de as instituições públicas profissionalizantes assumirem o compromisso em promover mudanças significativas na vida dos invisíveis, entre os quais o egresso do sistema prisional, para que um dia este possa ter a possibilidade de ser reinserido ao convívio social e ter a oportunidade de se tornar um cidadão crítico, autônomo e emancipado, a fim de poder contribuir com a sociedade. Os projetos voltados a atender as minorias excluídas, aos invisíveis, não têm dado continuidade nas instituições públicas de ensino profissional e nisso incluo o IFG, porque precisam de verbas específicas para serem implementados, assim como o Projeto Alvorada.

Nesse sentido, embora o atual governo prefira um "bandido morto" a um "ex-bandido" estudando, não é possível jogar toda a culpa no executivo que governa o país. Falta também atitude política e iniciativa das instituições públicas de ensino profissional em voltar o seu olhar para os invisíveis e excluídos socialmente. Anualmente estas instituições organizam um cronograma financeiro para o ano acadêmico sequencial e eu me pergunto: quanto deste orçamento é separado a projetos de formação profissional para quilombolas, mulheres, indígenas, presos e egressos do sistema prisional?

Ainda falta muito para que a educação e especificamente a educação profissional seja tratada como um direito e não um privilégio para os egressos do sistema prisional. Os documentos oficiais das instituições de ensino profissional vinculadas à Secretaria de Educação profissional e Tecnológica (SETEC) vêm emanados pelas teorias marxistas e o desdobramento delas. Entretanto, a formação humana, integral e omnilateral precisam estar para além da teoria. 
Tais teorias precisam estar na prática de professores e de gestores que têm em suas mãos a "caneta" que pode "assinar" a possibilidade de reinserção dos egressos do sistema prisional, ao convívio social, pela educação profissional.

\section{Referências}

BRASIL. [Constituição (1988)]. Constituição da República Federativa do Brasil de 1988. Brasília, DF: Senado Federal, Centro Gráfico, 1988.

BRASIL. Lei ${ }^{\circ}$ 9.394, de 20 de dezembro de 1996. Estabelece as diretrizes e bases da educação nacional. Diário Oficial: seção 1, Brasília, DF, ano CXXXI, n. 248, p. 27.833 27.841, 23 dez. 1996.

BRASIL. Ministério da Justiça e Segurança Pública. Departamento Penitenciário Nacional. Levantamento nacional de informações penitenciárias: atualização - junho de 2017. Brasília: Departamento Penitenciário Nacional, 2017. Disponível em: \&lt;http://depen.gov.br/DEPEN/noticias-1/noticias/infopen-levantamento-nacional-de informacoes-penitenciarias-2016/relatorio_2016_22111.pdf\&gt. Acesso em: 7 out. 2020.

CAPELLER, W. O direito pelo avesso: análise do conceito de ressocialização. Revista Temas, Sociedade, Direito e Saúde, São Paulo, v. 2, n. 2, p. 127-134, 1985.

CIAVATTA, M. A formação integrada: a escola e o trabalho como lugares de memória e de identidade. Trabalho necessário, Niterói, v. 3, n. 3, p. 1-20, 2005.

COSTA, R. L. da. Educação profissional técnica de nível médio a distância: estudo da mediação docente no modelo da rede e-tec Brasil na rede federal. 2015. Tese (Doutorado em Educação) - Pontifícia Universidade Católica de Goiás, Goiânia, 2015.

GANDOLFI, P. E. et al. O egresso do sistema prisional: educação escolar, emprego e inclusão social. Direito e Justiça (URI), Santo Ângelo, v. XI, p. 145-162, 2011.

GARRIDO, J. D. As fontes orais na pesquisa histórica: uma contribuição ao debate. Revista Brasileira de História, Memória, História, Historiografia, São Paulo, v. 13, n. 25/26, set./ago. 1993.

GRAMSCI, A. Cadernos do cárcere. Os intelectuais. O princípio educativo. Jornalismo. 2. ed. Rio de Janeiro: Civilização Brasileira, 2001.

INSTITUTO FEDERAL DE EDUCAÇÃO, CIÊNCIA E TECNOLOGIA DE GOIÁS. PDI/IFG 2019-2023. Plano de Desenvolvimento Institucional, 2019. Disponível em: https://www.ifg.edu.br/attachments/article/11546/PDI_IFG_2019_2023.pdf. Acesso em:15 nov. 2019.

JULIÃO, E. F. A ressocialização através do estudo e do trabalho no sistema penitenciário brasileiro. 2009. Tese (Doutorado em Ciências Sociais) - Programa de Pós-Graduação em Ciências Sociais do Instituto de Filosofia e Ciências Humanas da Universidade do Estado do Rio de Janeiro, Rio de Janeiro, 2009. 
JULIÃO, E. F. A ressocialização por meio do estudo e do trabalho no sistema penitenciário brasileiro. Em Aberto, Brasília, v. 24, n. 86, p. 141-155, nov. 2011. Disponível em: http://emaberto.inep.gov.br/index.php/emaberto/article/viewFile /2576/1765. Acesso em: 16 set. 2019.

LEMOS, A. M.; MAZZILLI, C. P.; KLERING, L. R. Análise do trabalho prisional: um estudo exploratório. Revista de Administração Contemporânea, Maringá, v. 2, n. 3, p. 129149,1998 .

MANACORDA, M. A. Marx e a pedagogia moderna. 2. ed. Campinas: Alinea, 2010.

MIRABETE, J. F. Execução Penal. Comentários à Lei 7.210, de 11-7-1984. 11. ed. São Paulo: Atlas, 2004.

OLIVEIRA, P. J. J. de. Direito ao trabalho do preso: uma oportunidade de ressocialização e uma questão de responsabilidade social. Revista do Curso de Direito da Faculdade da Serra Gaúcha - FSG, Caxias do Sul, ano 3, n. 6, p. 91-103, 2009.

PONTES, M. S. C. Qualificação profissional à população carcerária do sistema penitenciário do Estado do Pará: uma proposta de enfrentamento a reincidência. 2013. Trabalho de Conclusão de Curso (Graduação) - Superintendência do Sistema Penitenciário do Estado do Pará, 2013. Disponível em: http://www.susipe.pa.gov.br/sites/default/files/ QUALIFICACAO\% 20PROFISSIONAL.pdf. Acesso em: 19 mar. 2019.

RAMOS, M. N. Concepção do Ensino médio integrado. São Paulo: Cortez, 2005. Disponível em: http://www.iiep.org.br/curriculo_integrado.pdf. Acesso em: 02 mar. 2020.

ROCHA, V. F. T.; LIMA, T. C. B.; FERRAZ, S. F. S.; FERRAZ, S. B. A inserção do egresso prisional no mercado de trabalho cearense. Revista Pensamento Contemporâneo em Administração, Niterói, v. 7, n. 4, p. 185-207, 2013. Disponível em: http://www.spell.org.br/documentos/ver/30682/a-insercao-do-egresso-prisional-no-mercadode-trabalho-cearense/i/pt-br. Acesso em: 19 mar. 2019.

SHECAIRA, S. S.; CORRÊA JUNIOR, A. Pena e Constituição. São Paulo: RT, 1995.

SOUZA, R. L; SILVEIRA, A. M. Mito da ressocialização: programas destinados a egressos do sistema prisional. SER Social, Brasília, v. 17, n. 36, p. 163-188, jan./jun., 2015.

SOUZA, R. L; SILVEIRA, A. M. Egressos do sistema prisional no mercado formal de trabalho: oportunidade real de inclusão social? Revista de Políticas Públicas, Maranhão, v. 21, n. 2, p. 761-780, 2018.

VIEIRA, E. L. A construção da memória da cultura escolar prisional do Colégio Estadual Mário Quintana: entre o instituído e o instituinte. 2014. Tese (Doutorado em Memória Social) - Universidade Federal do Estado do Rio de Janeiro, Rio de Janeiro, 2014.

WAUTERS, E. A reinserção social pelo trabalho. 2003. Monografia (Especialização em Modalidades de Tratamento Penal e Gestão Prisional) - Universidade Federal do Paraná, Paraná, 2003. Disponível em: http://www.depen.pr.gov.br/arquivos/File/monografia _ednaw.pdf. Acesso em: 08 jan. 2019. 
Recebido em julho de 2020.

Aprovado em novembro de 2020. 